\title{
As máquinas de complexidade: diálogo com Edgar Morin ${ }^{1}$
}

\author{
Juliana Michelli da Silva Oliveira² \\ ORCID: 0000-0002-0588-5261 \\ Rogério de Almeida ${ }^{2}$ \\ ORCID: 0000-0002-6720-1099
}

\section{Resumo}

A presença da máquina como modelo de conhecimento tem assumido progressiva importância nas sociedades contemporâneas, sobretudo em razão do uso ampliado das máquinas cognitivas, as quais reconfıguram a organização das atividades produtivas, educativas, sociais e culturais. As consequências da utilização da máquina para o pensamento e fazer humanos, bem como a participação desse artefato como referência de funcionamento aos seres vivos e às sociedades são exploradas na obra $O$ método, do filósofo e sociólogo francês Edgar Morin. Buscando compreender o significado da máquina ou, mais precisamente, do ser-máquina no pensamento complexo e confrontar as hipóteses de trabalho do doutorado intitulado $A$ vida das máquinas: imaginário dos autômatos em 0 método de Edgar Morin, realizou-se uma entrevista com o autor no CNRS-Sorbonne, em Paris, atividade integrante do período de pesquisa desenvolvido na Universidade Grenoble Alpes e concluído na Faculdade de Educação da Universidade de São Paulo. Na entrevista, depois de esclarecer quais são as bases da noção de ser-máquina e suas peculiaridades em relação às abordagens cartesianas e lametrianas, o autor discorre sobre a importância do imaginário na produção do conhecimento e comenta as imagens pouco usuais que atribui às máquinas, como Pétrouchka. Por fim, Morin acentua a ideia de que os seres vivos são máquinas não triviais e não podem ser reduzidos aos determinismos que caracterizam as máquinas artificiais (artefatos), pois significativa parte de sua produção se dá a partir de processos criativos e auto-organizados.

\section{Palavras-chave}

Pensamento complexo - Ser-máquina - Imaginário da máquina.

1- Tradução do francês de Juliana Michelli da Silva Oliveira.

2- Faculdade de Educação da Universidade de São Paulo. Contatos: jumioliveira@gmail.com; : rogerioa@usp.br. 


\section{Machines of complexity: dialogues with Edgar Morin}

\section{Abstract}

The presence of the machine as a model of knowledge has gained increasing importance in contemporary societies, especially because of the amplified use of cognitive machines that have reconfigured the organization of productive, educational, social, and cultural activities. Edgar Morin dissects in his work, La méthode, the consequences of using machines for human thought and action, as well as the consequences of this artifice being our reference for optimal human and societal functioning. An interview with this author was performed at CNRS-Sorbonne Paris as part of my PhD research, initially carried out at the University of Grenoble Alpes and concluded at the School of Education at the University of São Paulo. The goal of this interview was to better comprehend, in complexity theory, the meaning of the machine and, more precisely, of the machine-being, as well as to confront the hypothesis of my PhD thesis, named Machine Life: the imagery of machines in Edgar Morin's La méthode. After clarifying the pillars of the concept machine-being and its peculiarities in regard to the works of Descartes and La Mettrie, the author discoursed about the importance of imagery in the production of knowledge and mentioned the unusual images that he attributes to machines, such as Pétrouchka. Finally, Morin emphasizes the notion that human beings are non-trivial machines and must not be reduced to the determinisms that portray artificial machines (artifices), since most of human production occurs through creative and self-organized processes.

\section{Keywords}

Complexity theory - Machine-being - Machine imagery.

\section{Apresentação}

A descrição da máquina muda, e às vezes radicalmente, de acordo com uma mudança do ponto de vista.

Edgar Morin

0 conto A biblioteca de Babel, de Jorge Luis Borges, inicia-se com uma epígrafe retirada da obra $A$ anatomia da melancolia, de Robert Burton, escrita no século XVII, que prepara o leitor para a matéria do texto: "Com tal arte podeis contemplar a variação das 23 letras...”. Na sequência, logo nas primeiras linhas do conto, em profícuo diálogo com Burton, o narrador propõe a equivalência que servirá de ponto de partida para sua reflexão sobre o conhecimento humano: o universo é uma biblioteca. Constituído por agrupamentos e arranjos de signos, esse universo pode assumir diferentes configurações, como sugere a referência de Borges: 
Com tal arte podeis contemplar a variação das 23 letras, que podem variar infinitamente, a ponto que as palavras complicadas e deduzidas daí não sejam contidas pelo compasso do firmamento; dez palavras podem variar em 40.230 modos diversos; com tal arte, podeis examinar [...] quantos homens, supondo que o mundo inteiro seja tão habitado quanto a França, tão fecundos, com tão longas vidas, hão de nascer dentro de 60.000 anos, também podeis demonstrar, como Arquimedes, quantos grãos de areia a massa do mundo inteiro poderia conter, se fosse só de areia, se já soubésseis quanto um pequeno cubo, do tamanho de um grão de mostarda, é capaz de conter, e infinitos outros problemas. (BURTON, 2012, p. 127).

Nessa biblioteca interminável narrada pelo escritor argentino, dispostas em diferentes livros, encontram-se todas as possíveis conjugações dos "símbolos ortográficos". Todas as combinações de letras, palavras, frases e ideias, as cacofonias e confusões, as narrativas escritas em todos os idiomas conhecidos ou desconhecidos, tudo o que foi dito, o que está sendo dito e o que será dito, inclusive o que escrevemos neste momento, todos esses momentos estão registrados nas páginas da biblioteca de Babel. Sobre o significado dessas escrituras, continua o narrador, muitas teses foram levantadas e continuam a ser escritas. Observou-se, por exemplo, que todos os livros têm uma lei fundamental, "por diversos que sejam, constam de elementos iguais: o ponto, a vírgula, as vinte e duas letras do alfabeto", e conclui-se que "não há, na vasta Biblioteca, dois livros idênticos” (BORGES, 2007, p. 73). E todos são responsáveis pela constituição do universo.

Diante desse universo de conhecimento, o narrador de Borges se aventurou procurando, de uma obra a outra, o catálogo dos catálogos, o livro total, que forneceria a chave desse repositório mais complexo que o imaginado pelos entusiastas do Big Data. Diante de nossas bibliotecas, mais restritas e especializadas que a de Babel, os esforços do filósofo e sociólogo francês Edgar Morin orientaram-se por outro projeto, que consistiu em reunir diferentes livros, articular saberes, enlaçar conhecimentos ou, dito de uma outra maneira, reverter o quadro de fragmentação disciplinar desse acervo que vimos construindo. Assim, o projeto do filósofo é mais preciso, mas não menos audacioso: propor, à sua maneira, uma versão de um conhecimento integrado, que siga uma frente oposta à simplificação, e estender o convite aos demais interessados, sugerindo que cada um assuma seu papel como articulador de saberes, como piloto do conhecimento. É disso que se trata o pensamento que ele denomina de complexo. 0 termo-chave da obra de Morin tem origem na palavra complexus, "o que abrange muitos elementos ou várias partes” (PETRAGLIA, 2002, p. 48) e se opõe à ideia de simplificação, compreendida como "a disjunção em entidades separadas e fechadas, a redução a um elemento simples, a expulsão do que não entra em um esquema linear” (MORIN, 2005, p. 36). Conforme o autor, plexus (entrelaçamento) advém de plexere (entrelaçar); portanto, complexo corresponde a "aquilo que é tecido conjuntamente" (MORIN, 1994, p. 55).

Nascido em Paris no dia 8 de julho de 1921 e registrado como Edgar Nahoum, participou da Resistência Francesa entre 1942 e 1944, respondendo pelo codinome Morin, posteriormente incorporado ao seu nome. Judeu de origem sefardita, filho único de Vidal Nahoum e Luna Beressi, Morin descende de marranos emigrados de Portugal a Amsterdã no século XVII e se considera não um desarraigado, mas um poliarraigado no 
Mediterrâneo, com heranças ibérica, italiana, salônica e balcânica, cujas raízes cresceram em solo francês. Embora se denomine um autodidata, cuja curiosidade se alimentou de novelas populares, cinema e música, formou-se em história, geografia e direito, estudando adicionalmente física, química, biologia e antropologia - para citar algumas de suas áreas de interesse (MORIN, 1994). Portanto, quando defende a inter ou a transdisciplinaridade o faz levando em conta sua própria trajetória, já que seu perfil ampara o projeto de entrelaçamento de saberes e caracteriza sua vasta produção, que abrange diferentes áreas do conhecimento.

Seu primeiro livro foi publicado em 1946, L'An zéro de l'Allemagne (O ano zero da Alemanha), depois de ter atuado no ano anterior como adido ao Estado Maior do Primeiro Exército Francês na Alemanha, e retrata a situação do povo alemão após a Segunda Guerra Mundial. Seus interesses múltiplos o conduziram a outros temas, como a reflexão sobre a morte numa perspectiva antropológica, publicada em L'Homme et la mort (O homem e a morte), de 1951. Em 1956, publicou Le Cinéma ou l'homme imaginaire (O cinema ou o homem imaginário), obra que associa o cinema à sede por duplos que permeia o interesse do homem por imagens, desde a pré-história. Um estudo de suma importância em sua produção anterior a La Méthode, apareceu em Le Paradigme perdu: la nature humaine (Enigma do homem - Para uma nova antropologia, em versão brasileira, ou Paradigma perdido: a natureza humana, em tradução de Portugal) de 1973, obra em que busca uma concepção bio-psico-social da espécie humana, associando o surgimento da cultura aos rituais de sepultamento, comuns entre os sapiens e os neandertais, e sugerindo o conceito de homo sapiens-demens para abarcar, ao lado da racionalidade, o imaginário e a passionalidade que nos caracterizam.

Principal referência de sua proposta de religação dos saberes, sua obra máxima, La Méthode ( $O$ método), teve seu primeiro volume publicado em 1977, a ele se somando outros cinco, em 1980, 1986, 1991, 2001 e 2004. Trata-se de um conjunto de livros que se esteia no uso de operadores cognitivos (ferramentas de complexificação do saber), de uma genealogia de organização, de circuitos de conceitos e da reintrodução do sujeito como parte do conhecimento. Na obra, encontram-se inovações linguísticas, compostas por neologismos e o uso alternativo de sinais gráficos (barras, parênteses e flechas), que unem palavras, sintagmas e conceitos. Nesse dialeto da complexidade, investigado por Sara Bonomo (2011), Morin procura reunir, desde as unidades lexicais das palavras, os diversos sistemas que as especializações disciplinares separaram. 0 uso da máquina no pensamento complexo, como noção e unidade física, parece advir desse anseio de ligação, tendo em vista que, enquanto objeto, a máquina é, ela mesma, uma combinação de partes e serve para articular elementos, função que também ocupará na obra de Morin.

Para a preparação de sua obra principal, Edgar Morin escolheu como interlocutor outro filósofo francês, nascido quatro séculos antes. A conversa foi longa: durou mais de trinta anos de trabalho e rendeu os seis tomos de $O$ método. No diálogo com René Descartes, Morin anuncia sua intenção de elaborar "um método, no sentido cartesiano, que permita bem conhecer a sua razão e buscar a verdade nas ciências" (MORIN, 2005, p. 28-29) e estabelece as orientações que o distinguem de seu antecessor, em entrevista a Pessis-Pasternak (1993, p. 88): 
Descartes escreve um "discurso do método", enquanto eu elaborei um "discurso da busca do método"; [...] ele acreditava que se podia deduzir um método a partir de princípios, enquanto eu busco esses princípios. Descartes formulou a grande distinção que dominou o mundo ocidental: entre o objeto e o sujeito, entre a natureza e o homem que deve dominá-la. A partir daí, o autoconhecimento cabia à filosofia e o conhecimento objetivo à ciência. Recuso essa disjunção.

Morin não nega a importância do legado do autor do Discurso do método, nem refuta a ideia de que a especialização disciplinar possa trazer relevantes frutos ao conhecimento, porém defende a necessidade de religar esses saberes. Isso porque acredita que "todo conhecimento simplificante, portanto mutilado, é mutilante, e se traduz por uma manipulação, uma repressão, uma devastação do real assim que ele é transformado em ação e singularmente em ação política” (MORIN, 2005, p. 468). Uma das estratégias utilizadas pelo filósofo da complexidade para reverter o panorama de simplificação disciplinar foi a consideração do imaginário como base estruturante do conhecimento. Tendo isso em vista, passou a explicitar as constelações de imagens que acompanham os conceitos com os quais trabalha, conforme preconizava Gilbert Durand (2001). Para Morin, em vez da imprecisão, as imagens trazem nova vida às abstrações e permitem que se reconheça o ente humano que as produziu. A identificação das imagens limitantes e a proposição de imagens mais frutuosas permitem a produção de um conhecimento mais consciente de suas escolhas, que assume sua transitoriedade e se reconhece como "uma forma de ficção - tanto de fingere, como fingimento ou manipulação, no sentido de forjar, quanto de ficticium, feitiço ou artificial, não natural -, uma forma muito particular de a consciência se comunicar consigo mesma e com as demais consciências humanas" (ALMEIDA, 2015, p. 95).

Como propõe Wunenburger (2003, p. 265-266), com essa aproximação entre conceitos e imagens, a ciência poderia reconhecer em suas representações "os recursos cognitivos dos símbolos e mitos (plurivocidade, analogia)" e, com isso, a racionalidade atuaria "em sinergia com a imaginação, [...] associada a exercícios de variações, de combinações, de inovações nas representações mentais". O estudo dessas imagens que acompanham os conceitos, sobretudo as concernentes às máquinas no pensamento complexo, foi um dos focos do doutorado intitulado $A$ vida das máquinas: o imaginário dos autômatos em 0 método de Edgar Morin, de Juliana Michelli S. Oliveira (2019), orientado pelo professor Rogério de Almeida, na Faculdade de Educação da Universidade de São Paulo, e pela professora Isabelle Krzywkowski, durante estágio de pesquisa na Universidade Grenoble Alpes (França).

No diálogo que Morin estabelece com a obra de Descartes, a máquina desempenha um papel diferente daquele designado pelo filósofo do século XVII. Sabe-se que os autômatos mecânicos foram utilizados como modelos de funcionamento de seres vivos por Descartes e permitiram a formulação da teoria dos animais-máquinas. Nela, os animais são considerados como máquinas semoventes, como puros maquinismos, e podem ser descritos como artefatos. Distanciando-se dessa visão mecanicista, Morin formula uma nova noção de máquina e desloca os artefatos da posição de modelos de conhecimento para a função de apêndices da práxis humana. Ao propor uma genealogia de sistemas guiada pela ideia de organização, Morin assumirá a máquina como o primeiro nível de 
articulação dos saberes complexos. Definida como todo sistema ${ }^{3}$ dotado de organização ativa (MORIN, 2005, p. 198), isto é, capaz de produzir organização, a máquina serve de elo comum entre os diferentes componentes da genealogia, na qual figuram sóis (arkhemáquinas), seres vivos (máquinas biológicas), sociedades (megamáquinas), linguagem, além dos artefatos (máquinas artificiais).

Na perspectiva moriniana, sóis são usinas de organização de matéria, pois produzem elementos mais pesados, como o carbono e os metais, a partir de elementos mais leves. $\mathrm{Na}$ sequência, os seres vivos são considerados máquinas biológicas que dependem de energia para se sustentarem, mantendo o bom andamento de suas funções com auxílio de sistemas de regulação, os quais evitam a ocorrência de variações desintegradoras que podem colocar em risco a integridade de suas operações. Diferentemente dos autômatos mecânicos, os seres vivos são máquinas não triviais, porque produzem internamente grande parte do que necessitam para viver: componentes, planos de funcionamento, organização, sistemas regulatórios, consertos, ainda que extraiam do ambiente seus alimentos e informações e nele eliminem seus resíduos. Logo, a produção das máquinas biológicas está voltada para o interior e equivale a uma produção-de-si, uma produção do ser (MORIN, 2005, p. 199). Por isso, no pensamento moriniano, é impossivel falar de máquina sem falar de existência e, nesse sentido, o termo mais adequado é o de ser-máquina, no lugar simplesmente de máquina. Dessa maneira, quando o autor se refere ao termo produção nos seres-máquinas, não alude somente ao significado mais usual na atualidade, relativo à produção industrial, mas também inclui as transformações sofridas pelo sistema para se manter e autorregular, tanto em seus aspectos maquinais da produção (repetições e reproduções) como em seus aspectos maquinantes (invenção e criação).

Em relação às máquinas artificiais (artefatos), estas dependem do exterior para realizar suas atividades, efetuar seus ajustes, regular suas operações, fornecer seus componentes, em síntese, o funcionamento e a produção das máquinas artificiais são comandados pelo meio externo. Na genealogia de sistemas, a máquina artificial assume posição secundária e, completa Morin (2005, p. 215), "foi por uma inquietante aberração que esta máquina fundamentalmente dependente, escravizada e escravizadora, desprovida de qualquer generatividade e de qualquer poiesis própria, foi promovida [...] como o arquétipo de toda máquina”. Eis uma das grandes diferenças entre a teoria de animais-máquinas de Descartes, que tem nas máquinas artificiais (autômatos mecânicos) seus modelos, e a proposta de Morin, cujas bases estão na organização das máquinas biológicas (seres vivos). Além de sóis, seres vivos, sociedades e linguagem, Morin também admite como componentes da família as máquinas de maior abrangência, formadas pela associação de máquinas entre si.

Ao lado dessa significativa mudança de referencial efetuada por Morin, há também uma considerável transformação no imaginário das máquinas em $O$ método. Como o autor adverte, é preciso deixar em suspensão o imaginário industrial para que possam ser admitidas outras imagens consteladas pela máquina:

3- Em Morin (2005, p. 132), o sistema corresponde à "unidade global organizada de inter-relações entre elementos, ações ou indivíduos", à unidade da complexidade. 
Assim como o conceito de produção, hoje mecanizado e industrializado, o conceito de máquina é pesadamente onerado por suas restrições e seus pesos tecnoeconômicos. Ele denota somente, na sua acepção corrente, a máquina artificial e conota seu ambiente industrial. Sendo assim, para bem conceber a máquina como conceito de base, precisamos nos desipnotizar das máquinas que povoam a civilização na qual estamos imersos. Não é preciso ser prisioneiro dessas imagens que surgem em nós: eixos, balanças, barras, bielas, botões, botaréus, cames, cardãs, blindagens, correntes, carrinhos, chapeletas, correias, cremalheiras, culatras, cilindros, embreagens, hélices, alavancas, manivelas, pinhões, pistões, molas, torneiras, engrenagens, válvulas, munhões, triângulos, alcaravizes, válvulas, volantes... Não sejamos prisioneiros da ideia de repetição mecânica, da ideia de fabricação standard. (MORIN, 2005, p. 203).

Tencionando compreender as novas imagens e referências culturais das máquinas que o filósofo dispõe em $O$ método, aprofundar a compreensão da importância da noção de ser-máquina em sua obra e confrontar as hipóteses de trabalho do projeto de tese $A$ vida das máquinas, foi realizada uma entrevista com Edgar Morin em 13 de fevereiro de 2018, às 15h45, no Institut des Sciences de la Communication, no Centre National des Recherches Scientifiques, Sorbonne, em Paris. Integrante do estágio de doutorado sanduíche ${ }^{4}$, a conversa realizada em língua francesa e presencialmente se desenvolveu ao longo de 40 minutos, dos quais são a seguir transcritos os trechos ${ }^{5}$ em que foi discutida a importância das máquinas na obra $O$ método.

$\mathrm{Na}$ entrevista, o autor esclarece as diferenças entre as máquinas artificiais e as máquinas biológicas, indica as referências que lhe serviram de base para a concepção de imaginário e para a criação da noção de máquina, trata das imagens que associou aos seres-máquinas, notadamente Pétrouchka, personagem do teatro russo de marionetes, e menciona a importância que a criação assume na produção dos seres vivos. Por compreender que as máquinas artificiais, fabricadas para atender as demandas da práxis antropossocial, se tornaram modelos de funcionamento para homens e sociedades, Morin reposiciona os artefatos em sua genealogia das máquinas e reabilita a noção de máquina, estabelecendo suas bases a partir da organização biológica. Ao propor outro imaginário da máquina, Edgar Morin interroga o automatismo industrial que demove a técnica de seus fins humanos, põe em relevo o aspecto mediador da noção de máquina e, com isso, cria novos arranjos nessa biblioteca interminável, propondo novos caminhos para a organização e o destino do conhecimento humano.

\section{Referências}

ALMEIDA, Rogério de. 0 mundo, os homens e suas obras: filosofia trágica e pedagogia da escolha. 2015. 204 f. Tese (Livre-Docência em Educação) - Departamento de Administração Escolar e Economia da Educação, Universidade de São Paulo, São Paulo, 2015.

4- Financiado pela Capes, pelo Programa de Doutorado-Sanduíche no Exterior (PDSE), processo n. 88881.132357/2016 01, e realizado no Centre de Recherche Imaginaire et Socio-Anthropologie (ISA), do LITT\&ARTS (Arts et pratiques du texte, de l'image, de l'écran et de la scène), sob orientação da diretora do laboratório Isabelle Krzywkowski e apoio do professor Florent Gaudez, do laboratório de Sociologia Émotion, Médiation, Culture, Connaissance (EMC2-LSG), ambos da Universidade Grenoble Alpes.

5- Agradecemos a François Malbranque, que gentilmente revisou a transcrição da entrevista. 
BONOMO, Sara. Sur la langue d’Edgar Morin. Hermès, La Revue, Paris, n. 60, p. 225-231, 2011/2.

BORGES, Jorge Luis. "A biblioteca de Babel”. In: BORGES, Jorge Luis. Ficções (1944). Tradução de Davi Arrigucci. São Paulo: Companhia das Letras, 2007. p. 69-79.

BURTON, Robert. Anatomia da melancolia: a segunda partição. A cura da melancolia. Tradução de Guilherme Gontijo Flores. v. 3. Curitiba: UFPR, 2012.

DURAND, Gilbert. As estruturas antropológicas do imaginário. São Paulo: Martins Fontes, 2001.

MORIN, Edgar. Mes démons. Paris: Stock, 1994.

MORIN, Edgar. 0 método 1: a natureza da natureza. Tradução de llana Heineberg. Porto Alegre: Sulina, 2005.

OLIVEIRA, Juliana Michelli S. A vida das máquinas: 0 imaginário dos autômatos em 0 método de Edgar Morin. 2019. 304 f. Tese (Doutorado em Educação) - Departamento de Administração Escolar e Economia da Educação, Universidade de São Paulo, São Paulo, 2019.

PESSIS-PASTERNAK, Guitta. Edgar Morin, contrabandista dos saberes. In: Do caos à inteligência artificial: entrevistas de Guitta Pessis-Pasternak. Tradução de Luiz Paulo Rouanet. São Paulo: Edunesp, 1993. p. 83-94.

PETRAGLIA, Izabel. Edgar Morin: a educação e a complexidade do ser e do saber. 7. ed. Petrópolis: Vozes, 2002.

WUNENBURGER, Jean-Jacques. Imaginário e ciências. In: ARAÚJO, Alberto Filipe; BAPTISTA, Fernando Paulo (Coord.). Variações sobre o imaginário: domínios, teorizações, práticas hermenêuticas. Lisboa: Instituto Piaget, 2003. p. 265-285. 


\section{A entrevista}

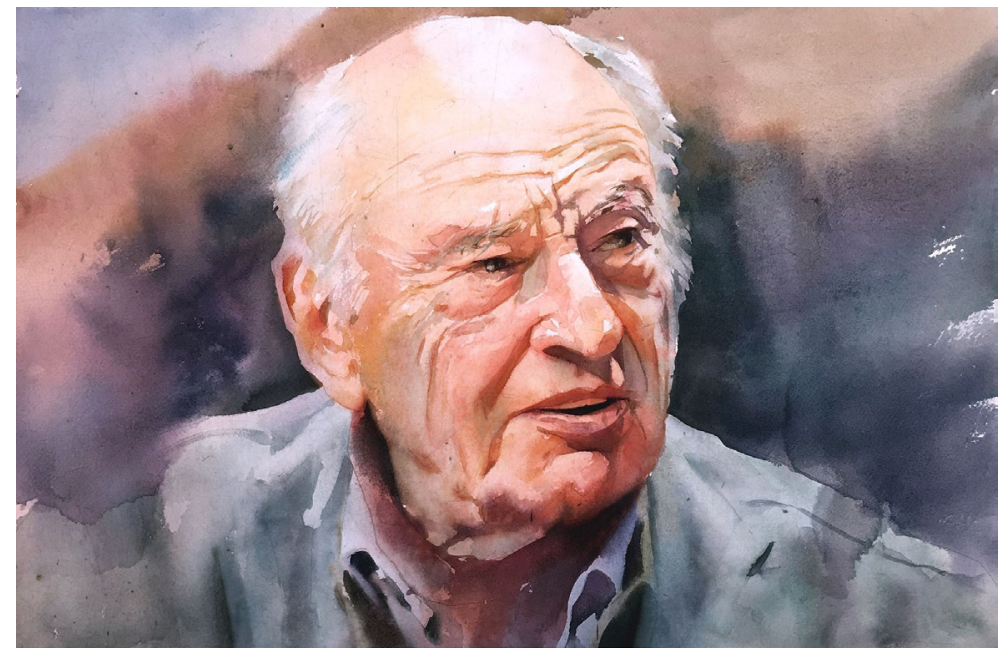

Assim entendida, no sentido forte do termo produção, a máquina é um conceito fabuloso. Ela nos leva ao coração das estrelas, dos seres vivos, das sociedades humanas. É um conceito solar; é um conceito de vida.

Edgar Morin

Fonte: Marcos Beccari (trabalho de aquarela fotografado).

Em $O$ método, a noção de máquina é utilizada para a elaboração de uma genealogia da organização desde a formação das estrelas até as sociedades humanas. Qual é a importância que o senhor atribui à noção de máquina no pensamento complexo?

De início, eu devo retomar um sentido mais antigo e muito mais amplo de máquina, posto que o sentido atual reduz a máquina à máquina artificial, à máquina que é fabricada pelo homem. Dizia-se, por exemplo, no século XVII, que a terra era uma máquina redonda. Depois, o filósofo La Mettrie, no século XVIII, falava de homem-máquina, enquanto no século anterior Descartes dizia que os animais eram máquinas.

Embora houvesse um sentido mais amplo de máquina, ele ainda assim possuía limitações, porque, quando Descartes falava sobre os animais-máquinas, ele queria dizer que não havia espírito e que não havia alma etc., quase como as máquinas artificiais. E, mesmo em La Mettrie, o homem-máquina era uma afirmação do materialismo, servia para dizer que o homem era determinado e nada mais. Então, para mim, a máquina é uma forma de organização muito refinada, que eu posso utilizar inclusive para uma estrela, pois a partir do momento em que eu concebo a estrela como uma organização que nasce da conjunção de duas forças contrárias, implosiva e explosiva, e que se autorregula, então eu vejo nesses elementos de regulação e organização os modos-máquina.

0 sentido em que eu considerei essa noção de máquina é um sentido que surpreende muito, mas, se a gente o admite, pode-se constatá-lo também na realidade humana, isto é, o fato de que nós somos também máquinas, máquinas que funcionam com energia, às vezes com a mesma combustão, 37 graus Celsius... Todos nós temos essas características de uma máquina extremamente complexa e com inumeráveis sistemas de regulação.

Então, essa minha proposta tem por objetivo introduzir um pouco de reflexão no modo de conhecimento redutor, para o qual a organização não tem um sentido central e que não integrou a teoria dos sistemas e, então, pelo mesmo motivo, não se interessa pela noção de máquina. É para introduzir essa noção, que para mim está no coração das coisas. 
Por que e de que maneira o senhor pensa que a noção de máquina pode continuar a ser utilizada como o primeiro grau de articulação entre os diferentes saberes? Pergunto isso porque o senhor propõe, em $O$ método, que a máquina é uma noção que pode articular diferentes disciplinas do conhecimento, posto que ela atravessaria a física, a biologia, a sociologia. Então, de que maneira o senhor pensa que essa articulação poderia continuar a ser realizada?

É o traço organizacional que não pode ser concebido como alguma coisa de redutora, porque é evidente que as máquinas vivas são máquinas não triviais. Essa é uma distinção que eu tomei de von Foerster e que utilizo muito. A máquina trivial é a máquina totalmente determinada, você coloca o programa e você tem o resultado, você faz o input, você tem output. No entanto, a máquina vivente, não apenas a humana, mas a viva, é inesperada, reações inesperadas podem acontecer, e, digamos, tudo o que é notadamente criativo é não trivial, também na evolução, na humanidade, nas artes etc. Então eu utilizo a máquina como um tema de ligação, mas não uma palavra redutora. É uma palavra que estabelece conexões, mas não é uma palavra que vai tudo explicar.

A noção de máquina e as referências que serviram de base para o pensamento complexo resultam de suas reflexões sobre a teoria da informação, a teoria cibernética e a teoria dos sistemas, além das noções que vieram da teoria de auto-organização. Apesar das grandes diferenças que marcam a sua proposta em relação a Descartes, por que o senhor considera indispensável o modelo de máquina para pensar a organização?

Porque entre as diferentes organizações existe o fato, no nível da complexidade, de que uma máquina tem seu sistema de produção, seu sistema de regulação, sua característica energética. A máquina é uma forma de organização, é isso que é importante. Mas, por exemplo, para falar da vida, eu falo de auto-organização, eu não digo automáquina, eu digo auto-organização. Para mim a palavra central é organização. Então, eu falo de autoeco-organização, e, você sabe, é isso que é o mais importante. A ideia de máquina revela que existem traços de organização no universo físico, no universo biológico e no universo humano, que há alguma coisa de comum entre eles. Mas eu repito: na vida, a máquina não é a trivial, ela não é determinista. E isto é importante: nós não somos somente máquinas, nós somos também máquinas.

Ao analisar a bibliografia de $O$ método, nota-se que o senhor se dedicou à leitura de vários textos relacionados ao estudo de símbolos, mitos e imaginário. Constata-se a presença de autores como Gilbert Durand, Gaston Bachelard, Henry Corbin, Roger Caillois, Ernst Cassirer, Jean-Pierre Vernant, Marcel Détienne, Mircea Eliade e HansGeorg Gadamer. Quais são os autores mais importantes para a sua concepção de imaginário? Por quê?

Entre os autores que me influenciaram, há Bachelard. Há também o livro de Sartre sobre o imaginário e Gilbert Durand. Existem outras fontes, que não são teóricos do 
imaginário, mas que são pessoas que desenvolvem a qualidade do imaginário, como os romancistas. Também fui conduzido naturalmente, por exemplo, ao cinema, onde encontrei uma importância capital do imaginário.

Quando eu fiz meu primeiro trabalho importante, que se chama $O$ homem e a morte, foi ali que eu descobri o imaginário. Porque eu parti de uma concepção mais ou menos marxista, em que o mundo do mito, do imaginário é uma superestrutura, um elemento secundário. Fazendo este trabalho eu me dei conta de que ele era também importante: Homo faber em um polo e Homo imaginaire em outro polo também importante, que é igualmente fundamental no ser humano, além do lado produtor, técnico.

Esse tema é tratado em meu livro Le cinéma ou l'homme imaginaire, no que concerne a mito, crença, imaginário, sobretudo quando toma a forma de um mito ou de uma fé religiosa. Eu vi que isso tem uma importância fundamental. Nós temos a necessidade à noite de sonhar, de fabricar o imaginário, é alguma coisa de fundamental. Mesmo durante o dia nós temos fantasmas, devaneios etc... Foi muito mais uma evolução pessoal que me conduziu a colocar o imaginário, e, da mesma maneira, a compreender a diferença entre o humano e o animal, porque existem similaridades e diferenças... Então, foi no imaginário também que isso se realizou. Ainda que eu saiba que os animais sonham, existem estudos sobre isso, eles possuem também sua parte de imaginário, mas nós temos imaginário em pleno dia, no estado de vigília, e é isso que é interessante. Nós temos a necessidade de nutrir nosso imaginário com lendas, romance, filmes etc. Então, isso teve mais importância na evolução de meu trabalho que os autores que me influenciaram.

0 senhor explicita as diferenças entre as imagens e as narrativas que motivam suas reflexões (por exemplo Métis, Hefaísto e Atena) e as imagens de exploração (imaginário industrial) habitualmente ligadas à máquina e propõe mudanças. Cito um excerto da sua obra: "o ser vivo à imagem robótica e pinoquionesca do autômato artificial. Trata-se mais de conceber como um Pétrouchka, autômato escapado das linhas deterministas da antiga física, que vive, sofre, ama, morre e, quando morto, torna-se boneco de pano - eu quero dizer de materiais químicos" [MORIN, 2005a, p. 339]. Em $O$ método, Pétrouchka seria uma das imagens do organismo-máquina. Como o senhor conheceu o personagem Pétrouchka? Através do ballet de Stravinsky? 0 senhor assistiu ao espetáculo, ao ballet de Pétrouchka?

Sim, claro. Você viu? Pétrouchka é o pequeno Pierre. Ele me golpeou porque há uma música magnífica, uma história muito bela, porque há aquele que exibe as marionetes, três marionetes, Pétrouchka, o Mouro e a mulher... a Bailarina. É interessante que, em um dado momento, eles escapam, as marionetes se tornam seres vivos, até a morte. Mas, no fim, quando eles estão mortos, eles retornam como seres materiais, quer dizer, coisas materiais. Eu achei que é uma imagem muito bela e por isso eu gosto muito desse ballet.

Sobre Pétrouchka, conheci uma versão com o Nureyev. Comecei a estudar a origem do personagem e a recuperar as origens dele a partir da commedia dell'arte... Por que a imagem de Pétrouchka seria mais pertinente para representar o organismo- 
máquina antes que as imagens de autômatos frequentemente utilizadas e por que o senhor privilegiou uma figura antropomorfa?

É porque essa figura é muito curiosa, pois ela escapa em um dado momento do determinismo e se torna livre, e eu penso que é um pouco isso, esse símbolo, que é interessante para mim. É possível... porque eu estava muito tocado por isso. Mas você sabe, eu penso que nós não somos de nenhuma maneira... eu elimino os marionetistas, o exibidor de marionetes, mas eu penso que nós somos possuídos por forças inconscientes, muito profundas e permanentes, quer dizer que, por exemplo, eu falo com você, a máquina cerebral funciona, os neurônios, as sinapses estão em plena atividade, essa máquina que funciona aqui... eu comi agora, a saliva começou a absorver os alimentos e eles entraram no trato digestivo e começaram a se transformar.

Então, há toda uma parte enorme de minha vida que se situa de maneira totalmente inconsciente. No fim do meu livro A humanidade da humanidade, eu digo o paradoxo, isto é, nós somos inteiramente possuídos por forças que nos movem e das quais nós não somos conscientes. Mesmo quando eu falo com você, eu tenho um discurso intelectual, mas minha mão se move de maneira maquinal, minha língua se move de maneira automática e eu não tenho consciência. Você sabe, há todo este aspecto que me chama muito a atenção.

Há a esfera noológica, a nooesfera que nos possui.

É isso. Que nos possui. Voilà. Quer dizer, o paradoxo é que nossos espíritos, nossos cérebros produzem ideias e deuses que eles mesmos, embora os tenham produzido, se tornam nossos mestres. Isso que é interessante.

$\mathrm{Na}$ sua genealogia de máquinas o senhor propõe que a linguagem humana é uma máquina. De onde vem a expressão "máquina de linguagem"? Surgiu a partir da genealogia de máquinas ou é uma expressão utilizada por um linguista ou por outro autor? Qual é a ligação entre as outras concepções de língua como máquina (linguística) e a emergência da cibernética?

Não me lembro. Mas posso dizer que, efetivamente, nosso olhar sobre as coisas é um tipo de máquina, quer dizer, a linguagem, sendo produzida por nós, assim como os deuses, mitos, ela adquire uma autonomia, ela se torna criativa através da gente, as palavras novas aparecem, não sabemos quem as inventa, mas é alguém. Ou, dito de outra maneira, é uma máquina, ela própria, que coloca em marcha uma outra máquina. Eu falei em um outro momento de polimáquinas, que se encadeiam umas nas outras. Me pareceu útil isso.

Quais são as referências que o senhor considera as mais importantes para a caracterização da máquina de linguagem? Eu comecei a pesquisar essa noção e tenho buscado as primeiras referências. Localizei a noção de máquina de linguagem em Paul Valéry, quando ele fala de poesia, mas apenas esse autor. 
Mas é preciso antes se referir a Jakobson, à teoria estrutural da linguagem, que é uma estrutura que funciona a partir de si mesma com este mecanismo, paradigma e sintagma. Ao considerar as teorias estruturais da linguagem a gente vê bem que é essa maquinaria que funciona na seleção de palavras pelo paradigma e através do sintagma. É isso.

A noção de máquina corresponde ao primeiro nível de articulação dos saberes no pensamento complexo e se organiza a partir de dois eixos: a reprodução e a criação. Na sua opinião, a noção de máquina poderia ser utilizada para organizar as diferentes produções humanas, a partir da ideia da reprodução como mimese e a criação como produção de diferença?

A criação é alguma coisa de não predizivel, de início, quer dizer, a criatividade, a criação, são características que nós conhecemos na vida, porque a vida criou formas diversas no mundo vegetal, desde uma folha de grama até a sequoia, flores, tudo isso. No mundo animal, então, uma diversidade inacreditável. É a criatividade, que está já incluída na reprodução viva, que é um momento da criatividade e que está incluída na cerebralidade humana, capaz de fazer as obras de arte, musical, pintura etc. Eu creio muito mais na importância da palavra criatividade que na palavra máquina.

\section{Bibliografia selecionada}

MORIN, Edgar. Le Paradigme perdu: la nature humaine. Paris: Éditions du Seuil, 1973.

MORIN, Edgar. 0 cinema ou o homem imaginário. São Paulo: É Realizações, 2014.

MORIN, Edgar. A cabeça bem-feita: repensar a reforma, reformar o pensamento. Tradução de Eloá Jacobina. 3. ed. Rio de Janeiro: Bertrand Brasil, 2001.

MORIN, Edgar. A morte e a ferramenta. In: 0 homem e a morte. Tradução de Cleone Augusto Rodrigues. Rio de Janeiro: Imago Editora, 1997. p. 91-106.

MORIN, Edgar. Epistemologia da tecnologia. In: Ciência com consciência. Rio de Janeiro: Bertrand Brasil, 1999.

MORIN, Edgar. L'Aventure de La Méthode - suivi de "Pour une rationalité ouverte". Paris: Éditions du Seuil, 2015.

MORIN, Edgar. 0 método 1: a natureza da natureza. Tradução de llana Heineberg. Porto Alegre: Sulina, $2005 a$.

MORIN, Edgar. 0 método 2: a vida da vida. Tradução de Marina Lobo. Porto Alegre: Sulina, 2005b.

MORIN, Edgar. 0 método 3: 0 conhecimento do conhecimento. Tradução de Juremir Machado da Silva. Porto Alegre: Sulina, 2005c. 
MORIN, Edgar. 0 método 4: as ideias. Tradução de Juremir Machado da Silva. Porto Alegre: Sulina, 2005d. MORIN, Edgar. 0 método 5: a humanidade da humanidade. Tradução de Juremir Machado da Silva. Porto Alegre: Sulina, 2005e.

MORIN, Edgar. 0 método 6: ética. Tradução de Juremir Machado da Silva. Porto Alegre: Sulina, 2005f.

MORIN, Edgar. Mes démons. Paris: Stock, 1994.

Juliana Michelli da Silva Oliveira é doutora em Educação (2019) pela Universidade de São Paulo (USP), com estágio de pesquisa (2017-2018) no Centre de Recherche Imaginaire et Socio-Anthropologie da Université Grenoble Alpes, França. Mestre em Educação, graduada em Letras e em Ciências Biológicas pela USP.

Rogério de Almeida é professor associado da Faculdade de Educação da Universidade de São Paulo (FEUSP). Coordena 0 Lab_Arte (Laboratório Experimental de Arte-Educação \& Cultura) e 0 GEIFEC (Grupo de Estudos sobre Itinerários de Formação em Educação e Cultura). É editor assistente da Revista Educação e Pesquisa (FEUSP) e editor colaborador para a área de Educação da Revista Machado de Assis em Linha. Bacharel em Letras (1997), Doutor em Educação (2005) e Livre-Docente em Cultura e Educação, todos os títulos pela Universidade de São Paulo (USP). Pós-doutoramento na Universidade do Minho (2016). Trabalha com temas ligados a Cinema, Literatura, Filosofia Trágica e Imaginário. 